\title{
Mycobacterium leprae alters classical activation of human monocytes in vitro
}

\author{
Dorothy Fallows ${ }^{1}$, Blas Peixoto ${ }^{1}$, Gilla Kaplan² and Claudia Manca ${ }^{1 *}$
}

\begin{abstract}
Background: Macrophages play a central role in the pathogenesis of leprosy, caused by Mycobacterium leprae. The polarized clinical presentations in leprosy are associated with differential immune activation. In tuberculoid leprosy, macrophages show a classical activation phenotype (M1), while macrophages in lepromatous disease display characteristics of alternative activation (M2). Bacille Calmette-Guérin (BCG) vaccination, which protects against leprosy, can promote sustained changes in monocyte response to unrelated pathogens and may preferentially direct monocytes towards an $\mathrm{M} 1$ protective phenotype. We previously reported that $M$. leprae can dampen the response of naive human monocytes to a strong inducer of pro-inflammatory cytokines, such as BCG. Here, we investigated the ability of the pathogen to alter the direction of macrophage polarization and the impact of BCG vaccination on the monocyte response to $M$. leprae.

Findings: We show that in vitro exposure of monocytes from healthy donors to $M$. leprae interferes with subsequent M1 polarization, indicated by lower levels of M1-associated cytokine/chemokines released and reduced expression of M1 cell surface markers. Exposure to M. leprae phenolic glycolipid (PGL) 1, instead of whole bacteria, demonstrated a similar effect on M1 cytokine/chemokine release. In addition, we found that monocytes from 10-week old BCG-vaccinated infants released higher levels of the pro-inflammatory cytokines TNF- $a$ and IL-1 $\beta$ in response to $M$. leprae compared to those from unvaccinated infants.

Conclusion: Exposure to M. leprae has an inhibitory effect on M1 macrophage polarization, likely mediated through PGL-1. By directing monocyte/macrophages preferentially towards M1 activation, BCG vaccination may render the cells more refractory to the inhibitory effects of subsequent $M$. leprae infection.
\end{abstract}

Keywords: Mycobacterium leprae, Polarization, BCG vaccination, Cytokine, Macrophage, Innate immunity, Leprosy

\section{Background}

Macrophages play a central role in the pathogenesis of leprosy, a chronic debilitating disease caused by Mycobacterium leprae. Monocyte/macrophages show a dynamic plasticity, allowing them to respond to environmental stimuli by presenting a classical (M1) or alternative (M2) activation state [1]. M1-activated macrophages release high levels of pro-inflammatory cytokines with enhanced microbicidal activity; M2 macrophages produce inhibitory cytokines and are less responsive to stimuli [2,3]. Leprosy presents as a spectrum of clinical manifestations, associated with differential immune activation. While tuberculoid leprosy shows robust cell-mediated immunity

\footnotetext{
* Correspondence: mancacl@njms.rutgers.edu

'Public Health Research Institute, New Jersey Medical School, Rutgers

University, Newark, NJ, USA

Full list of author information is available at the end of the article
}

with predominantly M1-activated macrophages, lepromatous disease is characterized by strong humoral immunity and macrophages show an M2 phenotype $[4,5]$.

Bacille Calmette-Guérin (BCG) vaccination protects against leprosy and is associated with reduced burden of unrelated diseases, suggesting non-specific protection that may involve shaping innate immunity [6-8]. BCG vaccination has been shown to induce sustained changes in the phenotype of circulating monocytes, with greater pro-inflammatory cytokine production [9]. Moreover, ex vivo stimulation of peripheral blood mononuclear cells (PBMC) from 10-week old infants vaccinated at birth with BCG, revealed a gene expression signature similar to an M1 macrophage profile with down-regulation of M2-associated genes [10].

We previously reported that stimulation of naïve monocytes from healthy donors with $M$. leprae alone, or 
$M$. leprae followed by BCG, induced the release of cytokine/chemokines that are associated with negative regulation of inflammation [11]. M. leprae itself was a poor inducer of the pro-inflammatory cytokine TNF- $\alpha$, consistent with other reports [12]. However, when naïve monocytes were first stimulated by BCG and then exposed to $M$. leprae, the cells produced a pro-inflammatory cytokine profile matching that of BCG alone [11]. Here, we investigated the ability of $M$. leprae to interfere with M1 maturation of monocyte induced by exposure to IFN- $\gamma$ and M2 maturation induced by exposure to IL4/ IL13 in vitro. We also tested whether BCG vaccination, by favoring an M1 phenotype, may render the cells resistant to the inhibitory effects of $M$. leprae.

\section{Methods}

\section{Reagents}

Mycobacterium leprae Thai-53 from the National Hansen's Disease Programs Laboratory Research, Louisiana State University, Baton Rouge (American Leprosy Missions and the Society of St. Lazarus) [13-15] and BCG from Trudeau Institute (Mycobacterial Culture Collection No. 1011) were prepared as described [11]. Purified M. leprae PGL-1, obtained through the NIH Biodefense and Emerging Infections Research Resources Repository NIAID, NIH: NR-19342, was used as described [16]. Peripheral blood mononuclear cells (PBMCs) from 10-week old infants unvaccinated $(N=18)$ or BCG-vaccinated at birth $(N=20)$ were provided by Dr. Willem Hanekom, University of Cape Town, South Africa.

These studies were approved by the Institutional Review Boards of Rutgers University and the University of Cape Town (Pro2012001418, Pro0120110233).

\section{Monocyte preparation/stimulation}

PBMCs were isolated from buffy coat (New Jersey Blood Center) of healthy donors; monocytes were purified using anti-CD14 antibody-conjugated magnetic beads (Miltenyi Biotec, Auburn, CA) and allowed to adhere before treatment [11]. For M1 polarization, monocytes were exposed to IFN- $\gamma(10 \mathrm{ng} / \mathrm{ml})$ for $24 \mathrm{~h}$, then stimulated with LPS $(100 \mathrm{ng} / \mathrm{ml})$ for $19 \mathrm{~h}[3,17]$. M2 polarization was achieved by treatment with IL-4/IL-13(10 $\mathrm{ng} / \mathrm{ml}$ each) for $24 \mathrm{~h}$ $[18,19]$. To determine the impact of $M$. leprae, cells were exposed to M. leprae at multiplicity of infection (MOI) 5:1 or 20:1 (bacilli:cells) for $5 \mathrm{~h}$ prior to IFN- $\gamma$ priming (M1) or IL-4/IL-13 treatment (M2). Cell viability was confirmed by trypan blue exclusion (Life Technologies, CA). Controls included: M1 or M2 polarization alone, M. lepraestimulation alone, and unstimulated/untreated cells.

Monocytes were isolated from infant PBMCs by adherence [11], plated in 96-well plates $\left(1 \times 10^{5}\right.$ cells/well) in RPMI 1640/20 \% human serum, and exposed to $M$. leprae (MOI 5:1) or culture medium alone.
A

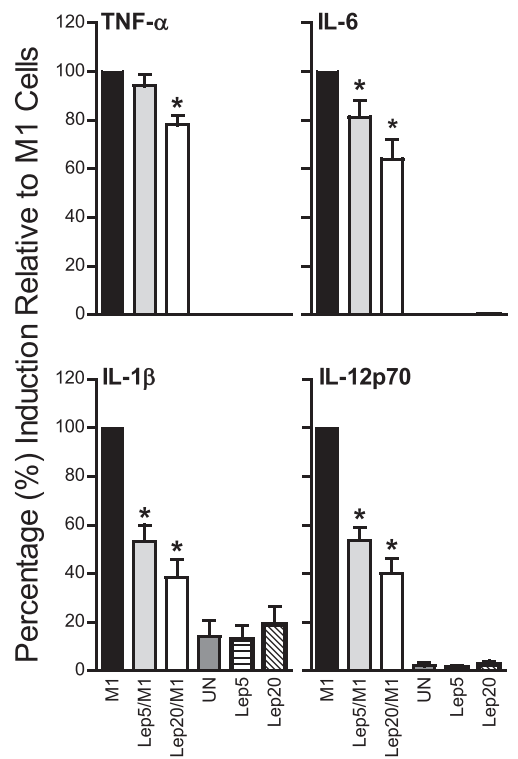

B
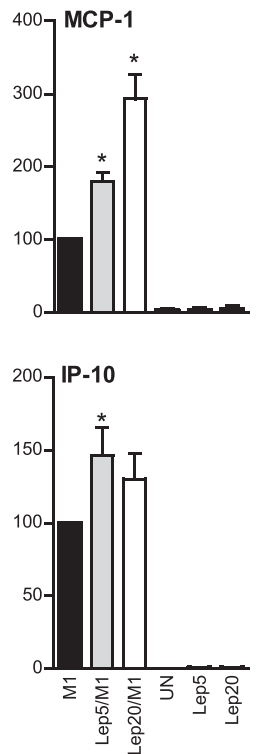

C
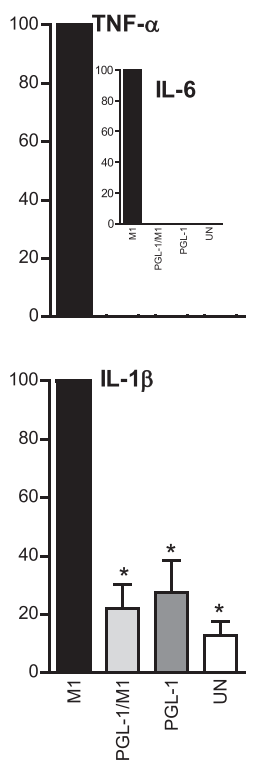

Fig. $1 \mathrm{M}$. leprae and its lipid component PGL-1 alter the release of cytokines and chemokines from M1 polarized monocytes. CD14 ${ }^{+}$cells were polarized towards M1 phenotype (M1) or pre-exposed for 5 h to the following: a-b M. leprae (MOI 5:1, Lep5 or 20:1, Lep20), c PGL-1 (50 $\mu$ g/mL) or cultured in medium alone (UN). Cell supernatants were collected at $48 \mathrm{~h}$ and cytokines/chemokines analyzed. Results are the mean \pm Sem: a-b 8 experiments ( 8 independent donors); and $\mathbf{c} 6$ experiments ( 6 independent donors) performed in duplicate. A 2-tailed paired t-test was used for statistical analysis ( ${ }^{*} P \leq 0.05$, relative to $\mathrm{M} 1$ cells) 


\section{Analysis}

Cell supernatants were removed after 48 h (M1) or $24 \mathrm{~h}$ (M2) and probed using a multiplex human cytokine/chemokine panel (Bio-Rad, Hercules, CA) according to manufacturer's instructions. Data/statistical analysis were done as described [16]. Cells were detached with EDTA (20 $\mathrm{mM}$ in PBS), washed with PBS, incubated with fluorescently-labeled antibodies against: CCR7, HLADR, CD80, CD86, and CD40 (BD Bioscience) (M1) or CD23 (M2), and analyzed on a FACSCalibur (BD Biosciences) using CellQuest (BD Biosciences) and FlowJo (Tree Star) software. Greater than 2,000,000 events per sample were analyzed.

\section{Results and Discussion}

M1 polarized monocytes (positive control) released high levels of TNF- $\alpha$ (mean $123.4 \pm 17.0 \mathrm{ng} / \mathrm{ml}), \mathrm{IL}-6$ (152.1 \pm $175.3 \mathrm{ng} / \mathrm{ml}), \quad \mathrm{IL}-1 \beta(0.3 \pm 0.07 \mathrm{ng} / \mathrm{ml}), \mathrm{IL}-12 \mathrm{p} 70(2.1 \pm$ $0.8 \mathrm{ng} / \mathrm{ml})$, MCP-1 $(6.2 \pm 2 \mathrm{ng} / \mathrm{ml})$, IP-10 (121 \pm 18.9$)$, Rantes $(11.6 \pm 2.3 \mathrm{ng} / \mathrm{ml}), \mathrm{MIP}-1 \alpha(22.5 \pm 3.2 \mathrm{ng} / \mathrm{ml})$ and MIP-1 $\beta(88.7 \pm 26.7 \mathrm{ng} / \mathrm{ml})$ compared to unstimulated/ untreated cells. Exposure of cells to M. leprae (MOI 5:1) prior to M1 polarization significantly reduced levels of
IL- 6, IL- $1 \beta$ and IL- $12 p 70$ by $19 \% \pm 27,47 \% \pm 25$, and $46 \% \pm 20$, respectively, compared to M1 controls (Fig. 1a). Pre-stimulation with M. leprae at higher MOI (20:1) led to further reduction; IL-6, IL-1 $\beta$ and IL-12p70 were reduced by $36 \% \pm 32,62 \% \pm 28$ and $60 \% \pm 25$, respectively. TNF- $\alpha$ was also significantly lowered by $22.2 \% \pm 5.0$ in response to $M$. leprae prestimulation, but only at higher MOI. In contrast, MCP-1 and IP-10 levels were significantly increased ( $P \leq 0.0001$ and $P \leq 0.05$, respectively) by $M$. leprae (MOI 5:1) pre-stimulation compared to M1 controls (Fig. 1b). While M. leprae at the higher MOI further increased levels of MCP-1 $(P \leq 0.001)$, IP-10 levels were not significantly different at the two MOIs (Fig. 1b). No consistent differences were seen in Rantes, MIP- $1 \alpha$ and MIP-1 $\beta$ (data not shown), suggesting that the impact of $M$. leprae on M1 polarization was selective. The inhibitory effect of $M$. leprae on M1 polarization observed here may involve interference with IFN- $\gamma$ signaling, as described in monocyte/macrophages exposed to Mycobacterium tuberculosis and in M. leprae-infected nude mice [20-22]. When monocytes were pre-exposed to PGL-1, instead of whole bacteria, the results were even more dramatic
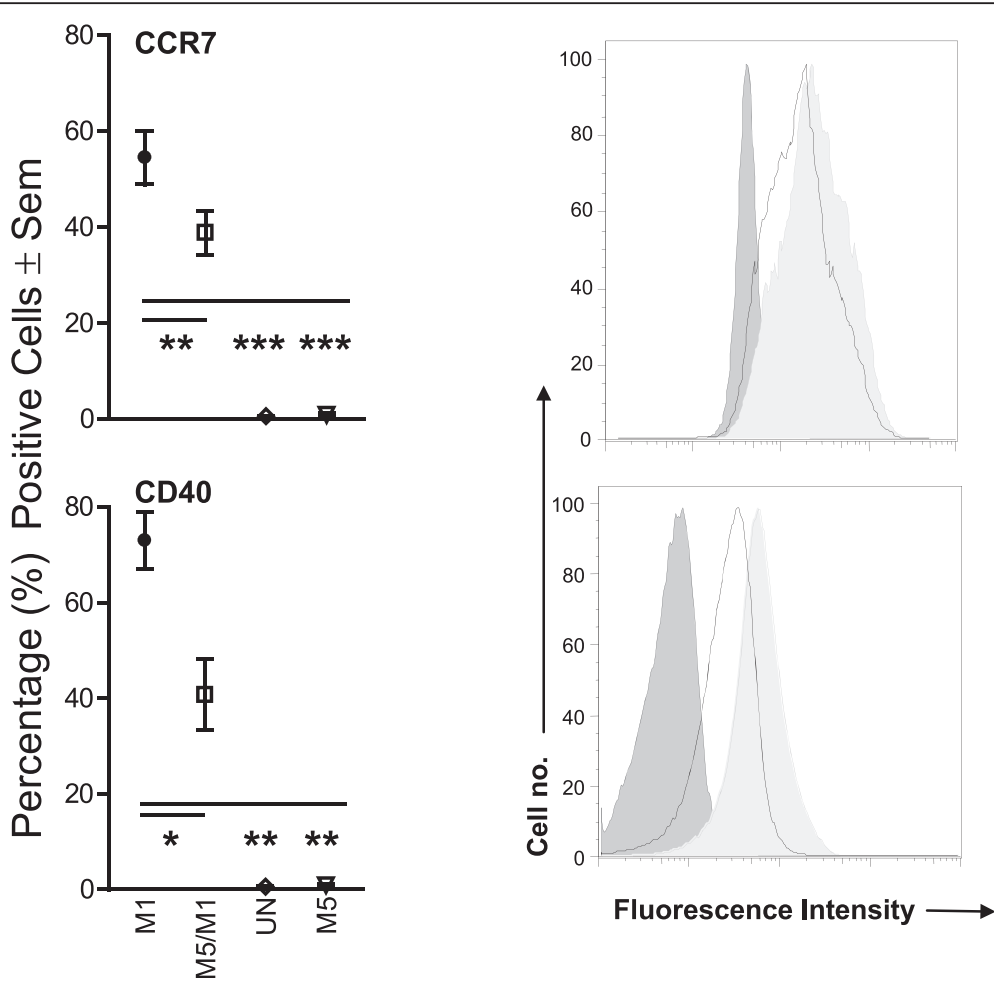

Fig. 2 Effect of M. leprae on M1 surface marker expression. CD14 cells were seeded in 24-well plates at the concentration of $5 \times 10^{5} /$ well and polarized (M1), or exposed to M. leprae at MOI 5:1 for $5 \mathrm{~h}$ prior to polarization (Lep5/M1). Additional conditions included stimulation of monocytes with M. leprae at MOI 5:1 (Lep5) and cells in culture medium alone without stimulation (UN). Changes in the percentages of CCR7 ${ }^{+}$and CD40 ${ }^{+}$cells were evaluated. A two-tail paired Student's $t$-test was used for the analysis. Results are representative of 6 experiments ( 6 individual donors); Histogram of one representative experiment. Dark gray: unstimulated cells; light gray: M1 cells; black line: Lep5/M1. ${ }^{*} P \leq 0.05 ;{ }^{* *} P \leq 0.001$; ${ }^{* * *} P \leq 0.0001$ 
(Fig. 1c). M1 polarized controls released high levels of TNF- $\alpha$ (mean $24,243 \pm 7,182 \mathrm{pg} / \mathrm{ml}), \quad$ IL-6 (50,348 \pm $8913 \mathrm{pg} / \mathrm{ml})$ and $\mathrm{IL}-1 \beta(75.5 \pm 23.2 \mathrm{pg} / \mathrm{ml})$, which were significantly reduced by PGL-1 pre-exposure (TNF- $\alpha$ : $6.7 \pm 3.9 \mathrm{pg} / \mathrm{ml} ; \quad$ IL- $6: 18.3 \pm 3.9 \mathrm{pg} / \mathrm{ml} ; \quad$ IL-1 $13: 12.6 \pm$ $2.0 \mathrm{pg} / \mathrm{ml}$ ). PGL-1 alone induced cytokine levels comparable to unstimulated/untreated controls. These results support previous reports that PGL-1 is an important determinant in $M$. leprae-monocyte interactions $[16,23,24]$.

M1 polarization also resulted in significantly increased percentages of cells expressing the surface markers CCR7 and CD40, relative to unstimulated/untreated controls. When monocytes were pre-exposed to $M$. leprae at low MOI, the percentages of $\mathrm{CCR}^{+}(P \leq 0.001)$ and $\mathrm{CD}_{40} 0^{+}(P \leq 0.05)$ cells were reduced compared to M1 polarization alone (Fig. 2). Pre-stimulation with $M$. leprae at higher MOI did not result in further reduction (data not shown). HLA-DR ${ }^{+}, \mathrm{CD}^{+} 0^{+}$and $\mathrm{CD}^{2} 6^{+} \mathrm{M} 1$ cell percentages were unaffected by $M$. leprae pre-stimulation. The mean fluorescence intensities (MFI) of CCR7, CD40 and CD80 in M1 cells were also significantly reduced by M. leprae pre-exposure (Table 1). M. leprae alone was comparable to unstimulated/untreated controls.

In contrast, the impact of $M$. leprae on expression of M2 macrophage markers was minimal. Pre-stimulation with M. leprae increased the MFI of CD23 (295 \pm 116 and $388.5 \pm 153$ at MOI 5:1 and 20:1, respectively) over M2 polarization alone $(242.7 \pm 108)$, with low levels produced by unstimulated/untreated cells $(24.9 \pm 12.3)$, and had no effect on IL-1Ra and IL-10 (data not shown). Thus, the effect of $M$. leprae on monocytes is primarily due to inhibition of M1 activation and does not appear to significantly affect M2 polarization.

Finally, we compared the effect of $M$. leprae on monocytes from 10-week old unvaccinated or BCG-vaccinated infants (Fig. 3). Levels of TNF- $\alpha$ and IL-1 $\beta$ released in response to $M$. leprae were significantly higher in monocytes from vaccinated infants than those from unvaccinated infants, while IL- 6 and MCP-1 showed trends

Table $1 \mathrm{M}$. leprae effect on the MFI of M1 surface markers

\begin{tabular}{|c|c|c|c|}
\hline & \multicolumn{3}{|c|}{ Phenotypic markers } \\
\hline & CCR7 & CD40 & CD80 \\
\hline M1 cells & $248.0 \pm 31.7$ & $51.6 \pm 6.3$ & $765.0 \pm 64.2$ \\
\hline Lep5 (5 h)/M1 & $167.1^{* *} \pm 22.6$ & $40.4^{*} \pm 6.5$ & $681.9 \pm 77.6$ \\
\hline Lep20 (5 h)/M1 & $152.2^{*} \pm 7.9$ & $46.3 \pm 7.8$ & $591.0^{*} \pm 70.1$ \\
\hline Unstimulated cells & $44.3^{* *} \pm 1.7$ & $6.5^{* * *} \pm 0.3$ & $16.6^{* * *} \pm 2.8$ \\
\hline Lep5 & $48.4^{* *} \pm 1.6$ & $7.8^{* * *} \pm 0.3$ & $20.3^{* * *} \pm 2.8$ \\
\hline Lep20 & $49.3^{* *} \pm 1.4$ & $7.8^{* *} \pm 0.4$ & $25.3^{* * *} \pm 3.3$ \\
\hline
\end{tabular}

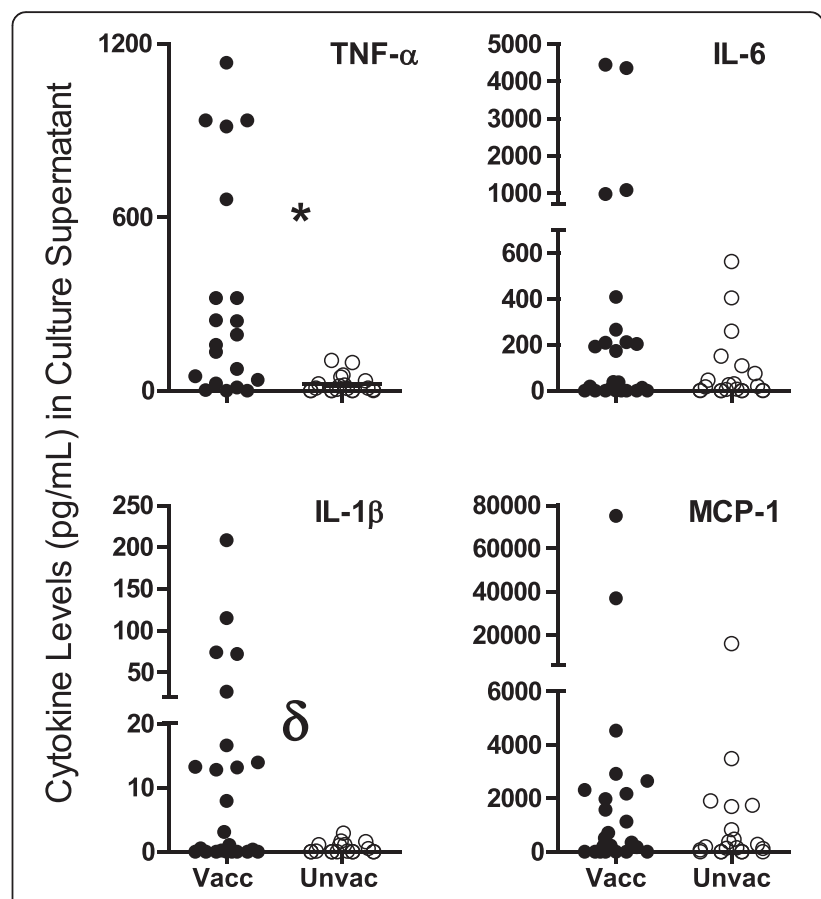

Fig. 3 Differential TNF- $a$ and IL-1 $\beta$ response to M. leprae stimulation of monocytes isolated from 10-weeks old BCG-vaccinated and unvaccinated infants. Monocytes were isolated from PBMCs of 10-week old infants, unvaccinated or BCG-vaccinated at birth, and stimulated for $24 \mathrm{~h}$ with $\mathrm{M}$. leprae. Data are expressed in $\mathrm{pg} / \mathrm{ml}$ minus the value of the corresponding unstimulated controls. A 2-tailed paired $t$-test was used for statistical analysis between cells stimulated with $M$. leprae. ${ }^{*} P \leq 0.001 ;{ }^{\delta} P \leq 0.05$

towards higher levels in vaccinated versus unvaccinated infants. These results demonstrate that in vivo activation of monocytes due to BCG vaccination may render the cells refractory to the inhibitory effects of $M$. leprae.

\section{Conclusion}

Exposure to $M$. leprae can alter the functional capacity of monocytes, which may diminish the efficacy of the host response to subsequent stimuli. Our results support increasing evidence suggesting that the innate immune response may be shaped by prior history of exposure, which could also explain the protection afforded by BCG vaccination against $M$. leprae and other unrelated pathogens.

\section{Abbreviations}

BCG: Bacille Calmette-Guérin; PGL-1: Phenolic glycolipid 1; PBMC: Peripheral blood mononuclear cells; M1: Classical macrophage activation; M2: Alternative macrophage activation; TNF-a: Tumor necrosis factor alpha; IL-13: Interleukin 1 beta; IL-12p70: Interleukin 12p70; IL-6: Interleukin 6; MCP-1: Monocyte chemotactic protein 1; IP-10: Interferon gamma-inducible protein 10; Rantes: Regulated on activation, normal T cell expressed and secreted; MIP-1a: Macrophage inflammatory protein 1 alpha; MIP1ß: Macrophage inflammatory protein 1 beta; IFN-ү: Interferon gamma; MOl: Multiplicity of infection; CCR7: C-C chemokine receptor type 7; HLA-DR: Human leukocyte antigen - antigen D related; CD40: Cluster of differentiation 40; CD80: Cluster of differentiation 80. 


\section{Competing interests}

The authors declare that they have no competing interests.

\section{Authors' contributions}

CM, DF, GK designed the study, interpreted the data and drafted the manuscript. $\mathrm{CM}, \mathrm{BP}$ performed the experiments, and data analysis. All authors have read and approved the final manuscript.

\section{Acknowledgements}

This work was supported by grants from NIH (R21Al101349) and from the New York Community Trust awarded to CM. The authors would like to thank Dr. Guibin Yang for technical advice. The funders had no role in study design, data collection and analysis, decision to publish, or preparation of the manuscript.

\section{Author details}

'Public Health Research Institute, New Jersey Medical School, Rutgers University, Newark, NJ, USA. ${ }^{2}$ The Bill \& Melinda Gates Foundation, Seattle, WA, USA.

\section{Received: 16 November 2015 Accepted: 8 March 2016}

Published online: 11 March 2016

\section{References}

1. Mege JL, Mehraj V, Capo C. Macrophage polarization and bacteria infections. Curr Opin Infect Dis. 2011;24:230-4.

2. Fairweather D, Cihakova D. Alternatively activated macrophages in infection and autoimmunity. J Autoimmun. 2009;33:222-30.

3. Mosser DM. The many faces of macrophage activation. J Leukoc Biol. 2003; 73:209-12.

4. Benoit M, Desnues B, Mege JL. Macrophage polarization in bacterial infections. J Immunol. 2008:181:3733-9.

5. Montoya D, Cruz D, Teles RM, Lee DJ, Ochoa MT, Krutzik SR, Chun R, Schenk M, Zhang $X$, Ferguson BG, et al. Divergence of macrophage phagocytic and antimicrobial programs in leprosy. Cell Host Microbe. 2009;6:343-53.

6. Sarno EN, Duppre NC, Sales AM, Hacker MA, Nery JA, de Matos HJ. Leprosy exposure, infection and disease: a 25-year surveillance study of leprosy patient contacts. Mem Inst Oswaldo Cruz. 2012;107:1054-9.

7. Shann F. The non-specific effects of vaccines. Arch Dis Child. 2010;95:662-7.

8. Blok BA, Arts RJ, van Crevel R, Benn CS, Netea MG. Trained innate immunity as underlying mechanism for the long-term, nonspecific effects of vaccines. J Leukoc Biol. 2015;98:347-56.

9. Kleinnijenhuis J, Quintin J, Preijers F, Joosten LA, Ifrim DC, Saeed S, Jacobs C, van Loenhout J, de Jong D, Stunnenberg HG, et al. Bacille Calmette-Guerin induces NOD2-dependent nonspecific protection from reinfection via epigenetic reprogramming of monocytes. Proc Natl Acad Sci U S A. 2012; 109:17537-42.

10. Fletcher HA, Keyser A, Bowmaker M, Sayles PC, Kaplan G, Hussey G, Hill AV, Hanekom WA. Transcriptional profiling of mycobacterial antigen-induced responses in infants vaccinated with BCG at birth. BMC medical genomics. 2009:2:10

11. Sinsimer D, Fallows D, Peixoto B, Krahenbuhl J, Kaplan G, Manca C. Mycobacterium leprae actively modulates the cytokine response in naive human monocytes. Infect Immun. 2010;78:293-300.

12. Oliveira MM, Charlab R, Pessolani MC. Mycobacterium bovis BCG but not Mycobacterium leprae induces TNF-alpha secretion in human monocytic THP-1 cells. Mem Inst Oswaldo Cruz. 2001;96:973-8.

13. Lahiri R, Randhawa B, Krahenbuhl J. Application of a viability-staining method for Mycobacterium leprae derived from the athymic (nu/nu) mouse foot pad. J Med Microbiol. 2005:54:235-42.

14. Shepard CC, McRae DH. A method for counting acid-fast bacteria. Int J Lepr Other Mycobact Dis. 1968;36:78-82.

15. Adams LB, Soileau NA, Battista JR, Krahenbuhl JL. Inhibition of metabolism and growth of Mycobacterium leprae by gamma irradiation. Int J Lepr Other Mycobact Dis. 2000;68:1-10.

16. Manca C, Peixoto B, Malaga W, Guilhot C, Kaplan G. Modulation of the cytokine response in human monocytes by mycobacterium leprae phenolic glycolipid-1. J Interferon Cytokine Res. 2012;32:27-33.

17. Vrancic M, Banjanac M, Nujic K, Bosnar M, Murati T, Munic V, Stupin Polancec D, Belamaric D, Parnham MJ, Erakovic Haber V. Azithromycin distinctively modulates classical activation of human monocytes in vitro. Br J Pharmacol. 2012;165:1348-60.
18. Bouhlel MA, Derudas B, Rigamonti E, Dievart R, Brozek J, Haulon S, Zawadzki C, Jude B, Torpier G, Marx N, et al. PPARgamma activation primes human monocytes into alternative $\mathrm{M} 2$ macrophages with anti-inflammatory properties. Cell Metab. 2007:6:137-43.

19. Meyer M, Huaux F, Gavilanes X, van den Brule S, Lebecque P, Lo Re S, Lison D, Scholte $\mathrm{B}$, Wallemacq $\mathrm{P}$, Leal T. Azithromycin reduces exaggerated cytokine production by $\mathrm{M} 1$ alveolar macrophages in cystic fibrosis. Am J Respir Cell Mol Biol. 2009;41:590-602.

20. Pai RK, Pennini ME, Tobian AA, Canaday DH, Boom WH, Harding CV. Prolonged toll-like receptor signaling by Mycobacterium tuberculosis and its 19-kilodalton lipoprotein inhibits gamma interferon-induced regulation of selected genes in macrophages. Infect Immun. 2004;72:6603-14.

21. Fortune SM, Solache A, Jaeger A, Hill PJ, Belisle JT, Bloom BR, Rubin EJ, Ernst JD. Mycobacterium tuberculosis inhibits macrophage responses to IFN-gamma through myeloid differentiation factor 88-dependent and -independent mechanisms. J Immunol. 2004;172:6272-80.

22. Sibley LD, Hunter SW, Brennan PJ, Krahenbuhl JL. Mycobacterial lipoarabinomannan inhibits gamma interferon-mediated activation of macrophages. Infect Immun. 1988;56:1232-6.

23. Dhungel S, Ranjit C, Sapkota BR, Macdonald M. Role of PGL-I of M. leprae in TNF-alpha production by in vitro whole blood assay. Nepal Med Coll J. 2008:10:1-3.

24. Liu PT, Wheelwright M, Teles R, Komisopoulou E, Edfeldt K, Ferguson B, Mehta MD, Vazirnia A, Rea TH, Sarno EN, et al. MicroRNA-21 targets the vitamin D-dependent antimicrobial pathway in leprosy. Nat Med. 2012;18: 267-73.

\section{Submit your next manuscript to BioMed Central and we will help you at every step:}

- We accept pre-submission inquiries

- Our selector tool helps you to find the most relevant journal

- We provide round the clock customer support

- Convenient online submission

- Thorough peer review

- Inclusion in PubMed and all major indexing services

- Maximum visibility for your research

Submit your manuscript at www.biomedcentral.com/submit 